\title{
EL TOPOS LÍRICO DE LAS HOJAS SECAS EN LA POESÍA LATINOAMERICANA DEL SIGLO XX
}

\author{
Dorde Cuvardic García \\ Ramón Pérez Parejo
}

\section{(9) $\mathbb{P Q \Theta \Theta}$}

Doi: https://doi.org/10.15517/rfl.v45i1.36672

URL: https://revistas.ucr.ac.cr/index.php/filyling 



\title{
EL TOPOS LÍRICO DE LAS HOJAS SECAS EN LA POESÍA LATINOAMERICANA DEL SIGLO XX
}

\author{
THE LITERARY TOPOS OF THE FALLING LEAVES IN THE LATIN \\ AMERICAN POETRY OF THE XX CENTURY
}

\author{
Dorde Cuvardic García \\ Ramón Pérez Parejo
}

\begin{abstract}
RESUMEN
El motivo de las hojas secas presenta en la literatura occidental un doble sentido: metapoético y afectivo-existencial. El propósito del presente artículo consiste en realizar un recorrido analítico e interpretativo sobre las diversas variantes, fórmulas lingüísticas y significados que ha recibido la función lírica afectivo-existencial de este motivo en la poesía latinoamericana del siglo XX, con especial incidencia en el Postmodernismo y las Vanguardias (cuya intención declarada fue rechazar la tradición literaria, en particular, la subjetividad legada por el Romanticismo, de la que el topos de las hojas secas es una de sus máximas expresiones), hasta llegar a las modulaciones semánticas que ha adquirido en la segunda mitad del siglo XX. Su núcleo semántico expresa el término de una relación amorosa (en el Romanticismo y Posromanticismo) o de una vida (en el siglo XX) y se materializa, sobre todo, en poemas de carácter narrativo.

Palabras clave: Hojas secas; topos; literatura latinoamericana; lírica; afectivo-existencial.
\end{abstract}

\begin{abstract}
The motif of the falling leaves has a double meaning in Western literature: meta-literary and affective-existential. The purpose of this article is to present an analytical and interpretative overview of the different variants, linguistic formulas, and meanings that the lyrical affectiveexistential function of this motif went through in twentieth-century Latin American poetry, particularly during the Postmodernismo and Vanguardias, until the semantic variations that it acquired in the second half of the twentieth-century and the beginning of the twenty-first. The explicit intention of the Vanguardias was to reject the literary tradition, in particular, the legacy of subjectivity of Romanticism, during which the topos of the falling leaves was one of its highest expressions. Its semantic core, we argue, expresses the end of a loving relationship (during Romanticism and Post-romanticism) or a life (in the twentieth-century), and it is depicted, mainly, in narrative poems.
\end{abstract}

Key words: Falling leaves; topos; Latin American literature; lyrical; affective-existential.

Dr. Dorde Cuvardic García. Universidad de Costa Rica. Profesor de la Escuela de Filología, Lingüística y Literatura. Costa Rica.

Correo electrónico: dcuvardic@yahoo.es

Dr. Ramón Pérez Parejo. Universidad de Extremadura. Profesor de la Facultad de Formación del Profesorado. Cáceres, España.

Correo electrónico: rpp@unex.es

Recepción: 19- 01- 18

Aceptación: 20-02- 18 


\section{Introducción}

Tal como se desprende de ciertos estudios de teoría literaria (Curtius, 1955 [1948], pp. 128-159; Guillén, 2005, p. 255), una de las modalidades para afrontar el estudio de la historia de la literatura consiste en analizar la evolución de los llamados topoi o tópicos, sistemas estereotipados de variaciones formales sobre un tema. Los autores expresan una temática codificada por una tradición, ligada esta última a un lenguaje, es decir, a unos clichés y diseños retóricos, lingüísticos, morfosintácticos y estructurales automatizados. Todos los escritores y oradores, al referirse a un determinado tema, han recurrido a ellos como si fuesen un almacén de provisiones (Pérez Parejo, 2002, p. 55).

Los tópicos, tanto al acuñarse como al utilizarse posteriormente, presentan unas coordenadas geográficas, históricas y contextuales que reflejan la sociedad en que surgen. Como declara E. R. Curtius, "el estilo en que se expresan [...] está siempre condicionado históricamente" (1955 [1948], p. 127). En este sentido, al crear un modelo de mundo (literario), los tópicos constituyen un testimonio de una forma de entender la vida. 'Son como son' por la sociedad en que fueron creados y, por tanto, responden al modelo o visión de mundo imperante en cierta época. Son 'fósiles' culturales, y ya sabemos, por la paleontología, que los fósiles hablan; solo hay que poner al oído atentamente para escuchar (Pérez Parejo, 2002, p. 56). Por poner unos ejemplos ilustrativos, los tópicos de las danzas de la muerte o de la batalla de amor, tan transitados en la Edad Media europea, a través de sus estructuras analógicas y correlaciones metafóricas, hablan de la ideología, de los miedos y de las formas de vida del Medievo (temor de Dios, dogma cristiano, resignación, vasallaje, vida caballeresca, honra y honor, concepción bélica de las relaciones personales y estatales, etc.) mejor que cualquier tratado de exégesis iconográfica medieval. Asimismo, la sustitución paulatina del tópico del universo como libro por la ciudad como enciclopedia alude a la urbanización y la secularización del mundo occidental. Y aun más, según Lennard G. Davis (2002 [1997], pp. 75-136), estos modelos de mundo literarios, cristalizados en tópicos, por lo general responden a la ideología del poder, la cual defiende siempre la posesión de la propiedad y los modos de vida de las clases hegemónicas, como, de hecho, ocurre en relación al clero (el tópico de las danzas de la muerte) y la aristocracia (el tópico de la batalla de amor).

Aunque las palabras empleadas en la expresión literaria de un tópico cambien parcialmente -de escritor en escritor y de periodo cultural en periodo cultural- el mensaje connotativo suele expresarse como una comparación o como una metáfora. Muchos de ellos, incluso, llegan a organizarse como verdaderas analogías (A es a B lo que C es a D). Por poner un ejemplo, el tópico de el universo es un libro que se puede leer sigue a grandes rasgos el siguiente argumento analógico: así como el libro (A) es interpretado por el lector (B), el universo (C) puede ser descodificado por su espectador (D) (Cuvardic, 2015).

En cuanto al tópico concreto de las hojas secas, ocasionalmente marchitas, caducas o muertas (en la literatura inglesa, falling leaves; en la francesa, feuilles mortes), alude denotativamente a unas hojas que se desprenden del árbol; caen y son, en algunos casos, arrastradas por el viento o arremolinadas por este último. En términos connotativos, se distingue en este tópico una función afectivo-existencial ("la hoja seca o marchita es el amor o la vida que muere", o bien "la hoja desprendida del árbol, arrastrada por el viento, es como el amor o la vida que ha llegado a su final y se disuelve en el olvido") y una función metaliteraria o metalinguística ("la hoja seca es como la palabra o el género literario que cae en desuso"). 
En cualquiera de los dos casos el diseño responde al uso recurrente de las analogías orgánicas en la teoría y en la práctica literaria de la Antigüedad, sean palabras o géneros literarios que caen en desuso (función metaliteraria o metalingüística), o bien el ciclo del amor, de la vida humana y del amor que llega a su término (función afectivo-existencial). En ambos casos, el contenido se acuña, en el marco del paradigma evolutivo de la historia literaria, desde metáforas orgánicas.

Las dos funciones, la afectivo-existencial y la metaliteraria o metalingüística, pueden cohabitar, de modo que los mensajes se tornan ambiguos. Esto ocurre incluso en los primeros casos hallados, como señala González Iglesias (2012, p. 55) en relación al Arte poética (Epístola a los Pisones) de Horacio o, en sentido inverso, en Follas-novas (1880) de Rosalía de Castro (2016), que se refiere en una primera lectura denotativa a la renovación de la esperanza humana, pero que puede remitir, en segunda lectura connotativa, al renacimiento de las letras gallegas.

La función metaliteraria o metalingüística de las hojas secas en la historia literaria occidental ya ha sido analizada e interpretada por Cuvardic (2015, pp. 409-421). Nos dedicaremos en el presente artículo a explicar la función afectiva-existencial en la literatura latinoamericana del siglo XX, en particular en el Postmodernismo, las Vanguardias y las últimas generaciones poéticas. Antes, sin embargo, señalemos rápidamente sus orígenes en la Antigüedad grecolatina y el contenido semántico básico de este tópico.

\section{Matizaciones teórico-semánticas y precursores clásicos}

Conviene realizar algunas matizaciones teórico-semánticas y, además, señalar algunas fuentes clásicas. Si el sujeto lírico describe una situación literal en la que una hoja seca o marchita se desprende del árbol, esta descripción denotativa no constituye un tópico. Este último debe contener una connotación trópica. Por ejemplo, la hoja marchita como descripción literal se ofrece en el "Libro I" de las Geórgicas de Virgilio". En cambio, en el "Canto VI" de la Ilíada de Homero, cuando Diomedes le pregunta a Glauco si procede de un linaje humano o divino, sí aparece como imagen poética, en particular, como analogía metafórica. Es decir, se emplea como tópico. Se usa, además, en su significado afectivo-existencial, pues se establece la correlación entre las hojas caídas del otoño con la muerte del ser humano ${ }^{2}$. No debe olvidarse que, en español, el término "árbol genealógico" -que nos habla de los diversos representantes de un linaje familiar- ilustra perfectamente la semanticidad del tópico: el ser humano y el árbol atraviesan las mismas fases evolutivas. Ambos nacen, se reproducen y, llegado el momento, el cuerpo, como la hoja de un árbol, no opone resistencia al viaje que le impone la Muerte (el viento), capaz de arrancar al cuerpo de la vida (a la hoja, del tronco), y conducir al individuo al destino final del olvido. Este último sema permite emparentar el tópico de las hojas secas con los del ubi sunt, el tempus fugit y otros que utilizan con frecuencia metáforas vegetales y que aluden o remiten simultáneamente a la fragilidad y al carácter efímero de la vida humana, como el carpe diem y el collige, virgo, rosas. En este último caso ya no son las hojas caducas de los árboles, sino las de las flores, pétalos que se marchitan, se desprenden y a veces caen. Así pues, el de las flores secas constituye un tópico 'hermano' del de las hojas secas, y en ocasiones se encuentran ambos tópicos en un mismo poema.

Es más conocido el uso afectivo-existencial del topos de las hojas secas, que expresa metafóricamente la fugacidad del amor o de la vida humana, frente al metalingüístico o meta- 
literario, como se puede apreciar en la Epístola a los Pisones, de Horacio. En todo caso, les une un núcleo semántico común: en el primer caso, la caducidad, la obsolescencia, la decrepitud de un amor o de una vida, y en el segundo del uso social de las palabras o las formas literarias.

Los escritores han encontrado una analogía entre la evolución vital del ser humano y la del árbol. Ambas son entidades, al fin y al cabo, vivas, orgánicas. El ser humano es concebido y nace; el árbol se cultiva y, a partir de una semilla, se convierte en una planta. Ambos crecen, llegan a la madurez y, por último, a la vejez y la muerte. Asimismo, si del ser humano se desprenden los hijos, del árbol también se pueden extraer 'vástagos', término empleado para referirse a la descendencia de los padres. De hecho, es común que se trasvasen metáforas del ámbito humano al vegetal. Y en metáfora de regreso a la esfera humana, si buscamos nuestros antepasados podemos reconstruir nuestro 'árbol genealógico'. Con todo, el árbol se regenera sobre su propio ser y esa regeneración es cíclica, mientras que la regeneración del ser humano se produce en un ser distinto, separado totalmente del primero. Su regeneración no es cíclica, como puede ocurrir cada año con los árboles durante la primavera. En cambio, la línea hacia la muerte es recta en el ser humano. Esta reflexión, ciertamente de tono elegíaco, late en los poemas que analizaremos.

La expresión tópica 'el otoño de la vida' se incorpora en el mismo campo semántico metafórico que el de las hojas secas, aplicadas al final de la vida humana. Una de las imágenes más prototípicas del otoño es, de hecho, la caída de las hojas. En particular, se considera el inicio de esta estación el momento en el que comienzan estas últimas a desprenderse de las ramas de los árboles (valga la redundancia, de hoja caduca). Y metafóricamente el otoño designa el inicio de la decadencia del ser humano. En todo caso, si bien el topos de las hojas secas en la historia de la poesía siempre se vincula con el 'otoño' (del amor, de la vida, del uso de las palabras, de los géneros), en cambio, no siempre que se dedique un poema al otoño aparecerá el motivo de las hojas secas. De hecho, en "El fin del otoño", de Nicasio Álvarez Cienfuegos, en "El otoño", de Alphonse de Lamartine, y en "Al otoño", de Keats, no hay rastro de este último motivo lírico.

El tópico de las hojas secas desarrolla su propia temporalidad narrativa. En primer lugar, se desprende la hoja del árbol. En muchos casos, ocurre un golpe de viento, que la arranca de la rama (del árbol del amor, de la vida, de la renovación linguiística y literaria); en segundo lugar, ocurre la caída; en tercer lugar, ya ubicada en el suelo, un golpe de viento posterior - un torbellino- arrastra la hoja por el suelo o la levanta por los aires. Con mayor precisión, el momento que se puede definir como núcleo semántico del tópico es el de la caída al suelo. Cuando, en algunos casos, las hojas remontan vuelo temporalmente gracias a un golpe de viento, se alude a una recuperación, solamente coyuntural, del amor o de la salud (y, ocasionalmente, de los recuerdos vivenciales).

El de las hojas secas es un ejemplo de metáfora orientacional, en particular, de la que expresa la semántica 'arriba es positivo' y 'abajo es negativo', como ocurre con la dicotomía vida-muerte, así como también es un ejemplo de la metáfora ontológica, que permite materializar, concretar o hacer visible, mediante una síntesis temporal, procesos de larga duración (la vida, el amor) (Lakoff y Johnson, 1986, pp. 50-52). La hoja cae hacia abajo, y esta última orientación queda revestida de connotaciones negativas vinculadas a la obsolescencia, la decrepitud, la muerte.

La variante existencialista de este topos se incorpora en aquellos poemas que, sin ser necesariamente elegías, adoptan un modo de sentir elegíaco (utilizando este concepto 
tal como lo emplea Friedrich Schiller (1995) en Sobre poesía ingenua y sentimental), caracterizado por la separación entre el ideal y la realidad, línea interpretativa que también sigue Souriau: "Lo elegíaco comporta generalmente un retorno hacia el pasado, y además un pasado perdido, fuente de lirismo interior" (1998, p. 493). Este sentido nostálgico, elegíaco, del topos, no se encuentra, en cambio, en su modalidad metapoética. ¿Qué se pierde, cuando se usa en la modalidad existencialista? La vida y el amor. En cambio, en el marco de la función metalingüística y metaliteraria del tópico se acepta como algo inevitable e incluso deseable que los arcaísmos sean sustituidos por neologismos y que los géneros evolucionen, caigan en desuso o surjan unos nuevos.

Las hojas secas, como tópico existencialista que permite visualizar la 'decadencia' de la vida de una persona, también se encuentra en la poesía lírica del Renacimiento y el Barroco. Es el caso de la famosa epístola que Francisco de Aldana le dirige a Arias Montano con motivo de la "contemplación de Dios y los requisitos della". Lo utiliza al inicio del autorretrato incorporado dentro del poema. Cumple la función de perfilar su etopeya o perfil psicológico: "yo soy un hombre desvalido y solo, / expuesto al duro hado cual marchita / hoja al rigor del descortés Eolo" (citado en Böhl de Faber, 1827, p. 57). El momento más apreciado en el devenir narrativo de este tópico es el momento en el que el viento desplaza por el aire la hoja arrancada: el tópico permite reforzar la idea de la soledad y de la orfandad del hombre 'arrojado' al mundo.

Conviene precisar que la antítesis del tópico queda representada por las hojas verdes. Casi siempre que se utiliza el tópico de las hojas verdes se alude a la vida o a la presencia del amor. El nacimiento de este último coincide, en la historia de la poesía, con la primavera. De ahí que se produzca la transferencia sinecdótica (símbolo particularizante) entre la primavera y sus materializaciones vegetales: hojas verdes, flores de pétalos abiertos. Pero en el mundo 'real', los amores no suelen coincidir con el inicio de la primavera. Por contraste, muchos amores concluyen al terminar el verano, es decir, al iniciarse el otoño (son 'amores de verano'). Del mundo empírico, esta experiencia ha saltado a la realidad literaria: el amor entre los amantes desfallece con la entrada del otoño.

Ya dijimos en la sección anterior que en la historia de la literatura occidental predomina el uso afectivo-existencial del topos de las hojas secas, frente al metalingüístico o metaliterario (cfr. Cuvardic, 2015, pp. 409-421). Esta última función ha sufrido una suerte paradójica o irónica. Fue utilizada para expresar la renovación lingüística, la sustitución de palabras caducas por otras nuevas, o de viejos procedimientos literarios por otros nuevos. Es decir, sirvió para expresar una de las más importantes ideas de historia de la literatura: la del arrinconamiento de la tradición por la innovación literaria. Pero como recurso literario también se volvió caduco y fue arrastrado por los 'vientos de cambio' de la modernidad literaria.

Según los poemas, se realiza un contraste implícito o explícito con el tópico, también de carácter alegórico, de las hojas verdes. Estas últimas surgen en primavera y aluden al nacimiento y desarrollo del amor y de la vida. El tópico de las hojas verdes se suele integrar en un tópico descriptivamente más amplio: el del locus amoenus. Es muy común contrastar el otoño, cuando la hoja está seca, mustia, marchita, con el momento en el que estuvo verde, en la primavera, y más exactamente, en abril. Se opera en este caso, según sea el poema, una comparación explícita o implícita entre dos situaciones temporales: la primavera esperanzada y el otoño mortecino. La antítesis temporal es existencial y afectiva: la primavera simboliza las esperanzas o realidades (afectivas, vitales) del yo lírico, y el otoño el recuerdo -desde la nostalgia- de estas esperanzas o realidades. 


\section{Evolución, subversión y negación de las hojas secas en la literatura latinoamericana del siglo XX: Posmodernismo, Vanguardias y segunda mitad del siglo XX}

Alejándonos excepcionalmente de la literatura latinoamericana, queremos iniciar este apartado con un ejemplo en lengua italiana porque inició la renovación del topos en la historia de la literatura occidental del siglo $\mathrm{XX}$, desautomatizando los usos y modulaciones que el tópico había adquirido en el Romanticismo, renovación en la que después profundizarían algunos escritores latinoamericanos. Nos referimos al poema "Soldati" (1918), de Giuseppe Ungaretti, pionero también de la estética del silencio, por cuanto expresa más con lo que calla que con lo que dice. El autor lo escribió en el bosque de Courton, en el frente occidental durante la Primera Guerra Mundial, concretamente en los alrededores de Reims:

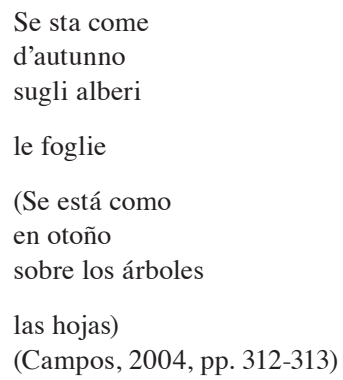

Obviamente, el poema está construido sobre la analogía metafórica entre las hojas secas del otoño y los soldados, unidos ambos por los semas de la fragilidad y de la amenaza de la muerte. De la secuencia del tópico al que hemos aludido (envejecimiento, desprendimiento, esparcimiento), el poema se instala en el momento climático, cuando las hojas están secas y a punto de desprenderse, lo que confiere al texto una máxima tensión. Utiliza una tercera persona impersonal (mediante el pronombre de uso impersonal o indeterminado "se") que generaliza el mensaje a todas las hojas y, por lo tanto, a todos los soldados. Unos y otros penden de un hilo en el frío otoñal de una tierra lejana y extranjera. Desde una estructura que recuerda al haiku japonés, que estuvo de moda en la literatura occidental en las primeras décadas del siglo XX, la versificación, corta y encabalgada en los primeros versos, no hace sino acentuar el riesgo de la caída de la hoja/soldado, que se puede producir por la simple brisa otoñal/por un disparo. No es casualidad, incluso, que el sintagma "le foglie" (las hojas) esté ocupando el último verso, connotando de este modo la amenaza del suelo y de la muerte. Como las hojas en otoño, los soldados están también mustios, marchitos, cansados, casi muertos, amenazados por el viento. Se desprende de esta analogía con las hojas secas la ansiedad y la inseguridad de los soldados ante un futuro incierto ${ }^{3}$.

Al ingresar en la literatura en español queremos destacar la utilización del topos de las hojas secas más allá del Romanticismo y del Posromanticismo. En el soneto "Las hojas secas" (Lienzos impresionistas, 1931), del poeta postmodernista venezolano Fernando Paz Castillo (1893-1981), la principal intención del enunciador radica en aludir al carácter azaroso, aleatorio, de la vida. De nuevo, como en Ungaretti, se introducen los semas de la fragilidad de la existencia humana. En el texto se establecen relaciones entre el tópico de las hojas secas y el del ubi sunt. Si algún campo semántico une ambos tópicos es el del olvido: 


\begin{abstract}
Una brisa ligera estremece la fronda.
Ruedan las hojas secas por la larga avenida.

¿A dónde van?... ¡Quién sabe a dónde va la ronda

De las hojas viajeras!
\end{abstract}

Hay una que impelida

Por voluntad secreta cae, riza una onda

Que genera otra y otra sobre el agua dormida.

Las demás todas huyen por la avenida honda

Que se hunde en la tarde, más allá de la vida.

Luego arrecia la brisa; las levanta; hay un vuelo,

Un tropel de hojas secas... Una sube, culmina

Y se mancha de sol y se pierde en el cielo...

Y al faltarle la brisa, como un pájaro muerto

Cae pesadamente... ¿Qué voluntad divina

Se ha llevado esta tarde las hojas de mi huerto? (Paz Castillo, 1988, p. 49)

En el presente caso identificamos connotaciones que no se encuentran en las manifestaciones románticas y posrománticas del topos. Se emplea un tono impresionista -en algunos casos, de tono apasionado; en otros, sereno- del que carecen los ejemplos de movimientos estéticos previos. El sentido del poema de Paz Castillo se completa, catafóricamente, en los dos últimos versos, a modo de epifonema, donde la experiencia 'objetiva' de las hojas rodantes queda personalizada. Las hojas han caído del huerto del yo lírico, es decir, del espacio protector y feliz, se han desprendido de los árboles. En la vida de la voz enunciativa, que hasta ahora ha sido gratificante, se han producido, calladamente, algunos acontecimientos desgraciados. Consideramos que el huerto que ha quedado vacío de hojas alude a la conciencia o mente del yo lírico del que han 'huido' los recuerdos.

El poema sigue el núcleo semántico de las hojas como recuerdos (no aluden al amor ni a la vida). Y para expresar el destino que sufren, el yo lírico enuncia una situación alegórica de tono impresionista. El proceso gradual de transformación de los recuerdos en olvido no se expresa en una tonalidad patética, apasionada, sino juguetona. Como sucede en otros poemas, las hojas ya se han desprendido de los árboles y las 'hojas secas' se acumulan en las sendas. Como paso previo a la disolución final (el olvido permanente), el poema se inicia en el preciso momento en el que las hojas yacentes en el suelo ruedan, gracias a un nuevo y ligero golpe de la brisa. Consideramos que la brisa responde a los recuerdos rescatados del olvido, a una memoria que revitaliza coyunturalmente pensamientos muertos. Apreciamos una equivalencia entre la imagen del poema de Paz Castillo y la imagen de las ideas poéticas, perteneciente a la "Introducción sinfónica" de las Rimas, de Gustavo Adolfo Bécquer, que se agitan y estremecen en tropel y en tumulto, para salir a la luz y adquirir la vestidura de la palabra, aunque muchas de ellas no lo logren y caigan en el olvido: "Mudos, sombríos e impotentes, después de la inútil lucha vuelven a caer en su antiguo marasmo: tal caen inertes en los surcos de las sendas, si cae el viento, las hojas amarillas que levantó el remolino" (Bécquer, 2001, p. 79).

Algunas hojas quedan individualizadas. En el poema de Paz Castillo, la hoja que, impelida por una voluntad secreta, cae en el agua dormida y riza una onda, que a su vez genera otra onda, remite a un recuerdo recuperado que, gracias a la llamada memoria involuntaria, genera otros recuerdos (en el poema, se genera un encadenamiento de ondas, una asociación de recuerdos, a partir del agua dormida o del agua del olvido). Otra hoja/recuerdo tiene el ansia de la trascendencia, de la eternidad, pero su impulso vital pierde fuerza pronto y cae 
en el olvido rápidamente. El uso de los puntos suspensivos le presta un suspense irónico a la imagen de esta segunda hoja. El azar y lo imprevisto (Doane, 2012) son las dos preocupaciones del pensamiento filosófico en el cambio del siglo XIX al siglo XX, dos conceptos que tanto el impresionismo literario como el pictórico pretenden describir, como ocurre en el presente caso.

Hace tiempo que el yo lírico experimentó un presente pleno y feliz. El tono es elegiaco: se trata de la aceptación resignada y serena de una pérdida. Esta última ha sido ya asumida hasta tal grado que el proceso paulatino del olvido se recrea desde una alegoría juguetona, ligera. Algún que otro recuerdo es gratificante y le deja un 'dulce' sentimiento al yo lírico, antes de quedar sumido en la nada. Por su parte, el olvido abrupto de un recuerdo que tuvo un atisbo de permanencia o eternidad (sublime, que se mancha de sol y asciende a las alturas) se representa como una hoja que termina por caer, después de remontar el vuelo varias veces; es, asimismo, como un pájaro muerto que se desploma pesadamente. Los recuerdos parecen llegar en tropel a la conciencia del sujeto lírico -para describir esta experiencia se emplea la imagen del vuelo que remontan las hojas-, pero rápidamente quedan olvidados, acontecimiento visualizado mediante las hojas que de nuevo caen al suelo.

Nos enfrentamos a una clásica metáfora orientacional: 'arriba' es 'recuerdo' y 'abajo' es 'olvido', que según sean los casos puede ser el suelo, pero que en otras oportunidades es el agua empantanada, dormida. Por último, otros recuerdos son olvidados rápidamente, sin quedar reactivados con mayor o menor éxito, sin dejar una dulce placidez en el estado de ánimo del yo lírico: son las hojas, la mayoría, que huyen 'por la avenida honda / Que se hunde en la tarde, más allá de la vida'. Se recrean en estos dos versos dos imágenes del habla coloquial: la imagen 'los recuerdos huyen precipitadamente' para aludir al proceso del olvido; y el 'pozo del olvido' -préstese atención al par 'honda' / 'hunde'- para aludir a los recuerdos que no son almacenados en la memoria a largo plazo y no son recuperados posteriormente. Al ocuparse de los mismos tópicos, el Posmodernismo elimina el patetismo del Romanticismo y el sentimentalismo del Posromanticismo.

La caída y el vuelo de las hojas secas son los momentos predilectos del Posmodernismo a la hora de representar este tópico, en lugar del desprendimiento del árbol. Con ello se pretende designar el carácter impredecible de la vida, así como la dirección del viento -en el caso de las fuerzas de la naturaleza- no se puede conocer de antemano. El momento en el que el viento se lleva las hojas caídas arremolinadas es destacado, asimismo, por la poeta cubana Dulce María Loynaz en "Hoja seca" (Versos, 1920-1938):

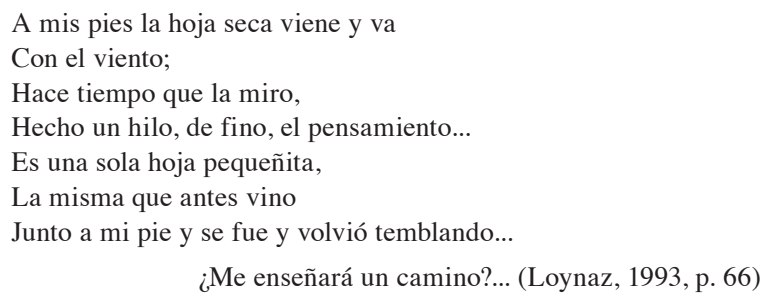

Es uno de los pocos poemas en los que el yo lírico queda incorporado en la escena del correlato objetivo. En el marco de la estética de lo nimio típica del Posmodernismo ya no se recrea la escena del tropel de hojas arremolinadas que, arrastradas por el viento, chocan unas con otras, sino que se representa una solitaria, pequeña y juguetona hoja (véase, también, el poema de Paz Castillo, donde dos hojas terminan por destacar de las demás). La hoja que 
se acerca y se aleja del yo lírico es el recuerdo recurrente, ocasionalmente recuperado en la memoria del sujeto; es la imagen que, de tanto en tanto, recrea en su mente y que deja en el hablante un estado de suspense, de meditación, de reflexión. Es el dulce recuerdo gratificante de una persona, tal vez procedente de una escena de su pasado íntimo. El recuerdo, ¿le dejará alguna enseñanza que le permita tomar decisiones en el futuro? Al igual que el poema de Paz Castillo, termina con una interrogación, que responde a la estilística de la atenuación, de la incertidumbre sosegada que adopta el sujeto de la poesía posmoderna ante los misterios de la existencia, de la vida o del amor.

El posmodernista mexicano Juan José Tablada también exploró el uso lírico del tópico en dos haikus, procedentes de Un día... Poemas sintéticos (1919). En "Hojas secas", el yo lírico, desde el presente de la enunciación, en un otoño bastante avanzado, la mirada dirigida hacia un jardín lleno de hojas secas le permite activar el recuerdo del mismo espacio en primavera, cuando sus árboles se encontraban llenos de hojas (recordemos, en estas coordenadas, el huerto del poema de Paz Castillo). La intención principal de este haiku es ofrecer la antítesis entre dos situaciones, la vida y la muerte, entre la altura de las ramas y la alfombra vegetal del suelo, sin que medie ningún conector entre presente y pasado ${ }^{4}$ :

El jardín está lleno de hojas secas

Nunca vi tantas hojas en sus árboles

Verdes, en primavera. (Tablada, 1971, p. 377)

En "Hotel", por el contrario, el yo-lírico se retira explícitamente de la enunciación. Los versos descriptivos buscan, mediante la selección de ciertos referentes, pertinentemente elegidos, destacar la inactividad, vacío y soledad de un complejo turístico que, por contraste -puede inferir el lector-, se encuentra lleno de vida en otras estaciones:

Otoño en el hotel de primavera;

En el patio de 'tennis'

Hay musgo y hojas secas. (Tablada, 1971, p. 377)

En este momento podemos hacer un alto en el camino y preguntarnos por los paralelismos expresivos entre el haiku y la forma expresiva sintética, breve pero semánticamente intensa, desde la que, en ocasiones, se ha materializado el tópico de las hojas secas. La expresividad contenida del Posromanticismo, fundamentada en sugerencias, en alusiones, prepara el camino para un impresionismo literario posmodernista, también alusivo y sugestivo, que se ocupará de trasvasar el haiku a Occidente, y que también incorpora los mismos valores de brevedad, alusividad y sugestividad.

El rechazo y burla de los tópicos del Romanticismo sentimental es una de las más conocidas reacciones contra la tradición literaria de las Vanguardias. No podía faltar tampoco la parodia de uno de los más conocidos, el de las hojas secas. Es el caso de "Y nada de hojas secas", de Andamios interiores (1922), de Manuel Maples Arce, en lo que se vino a llamar "Estridentismo mexicano". El lema "Y nada de hojas secas" hay que ponerlo en relación con el futurismo, el creacionismo y otros ismos vanguardistas que postulan la deshumanización del arte en términos orteguianos. Se trata de rechazar la tradición o, al menos, de intentar innovar sobre la base de referentes y términos imaginarios metafóricos que no remitan a la naturaleza, como se hace en la poesía tradicional y popular, sino al mundo contemporáneo. Si bien la tradición literaria no queda arrinconada totalmente, como han demostrado innumerables estudios, los escritores buscan muchas veces la sustitución de tópicos clásicos por otros 
vinculados con la modernidad (las innovaciones tecnológicas, los medios de comunicación). En otras ocasiones se opera una resignificación, desde la esfera de la cotidianeidad moderna, de los tópicos clásicos. Por último, el enunciador también puede posicionarse en el rechazo de los topos clásicos, como en "Y nada de hojas secas", donde el propósito del enunciador es repudiar todo tópico tradicional convertido en clisé por movimientos precedentes:

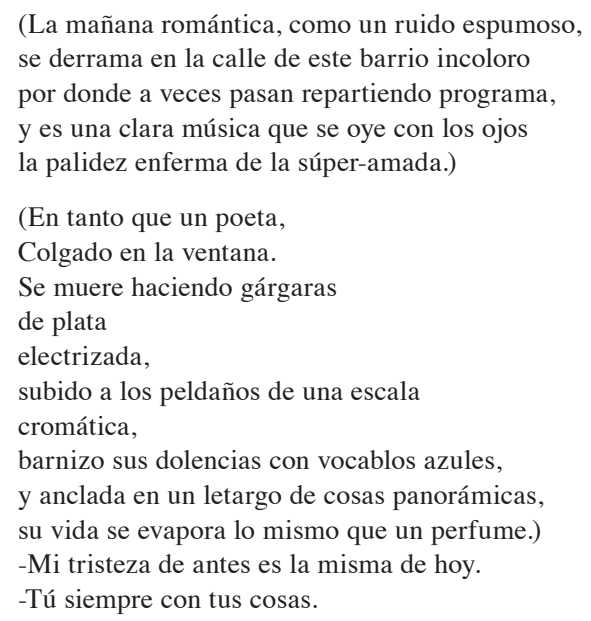

- ¡Oh, poeta, perdón!

(En el jardín morado

se rompe el equilibrio fragante de una flor.)

-Sol, blancura, etc., y nada de hojas secas.

-La vida es sólo un grito que se me cuelga al cuello

lo mismo que un adiós.

Hablemos de otra cosa

te lo ruego.

(Su voz

tiene dobleces románticos de felpa

que estuvo mucho tiempo guardada en naftalina,

y duerme en sus cansancios ingrávidos de enferma,

la elegancia de todas las cosas amarillas.)

(Y mientras la mañana, atónica de espejos,

estalla en el alféizar de la hora vulgar,

el dolor se derrama, lo mismo que un tintero,

sobre la partitura de su alma musical.) (Maples Arce, en García Maroto, 1999, pp. 76-77)

En el poema precedente se opera una burla de los clisés románticos: el sentimentalismo, el suicidio, etc. La primera estrofa se refiere a la popularización de la retórica lírica romántica, exageradamente exaltada, apasionada. Muy posiblemente, esta 'clara' música que se oye con los ojos, esta música - muy gráfica- de fácil comprensión sea la música popular que se difunde a través de los arrabales. La lírica, antes que un arte mimético, se considera como una manifestación artística expresiva: de aquí la asociación entre la poesía romántica y la música. Se menciona una de las más conocidas imágenes líricas de la poesía de este último movimiento literario: la amada melancólica, desfalleciente, enferma de tisis o tuberculosis. Otros muchos tópicos románticos son nombrados en el poema: escala cromática, dolencias, letargo, evaporación, perfumes, tristeza, jardín, flor y, por supuesto, hojas secas. 
Este tono, pretendidamente trascendental, queda repentinamente contrarrestado en la segunda estrofa con una escena ridícula: la de un poeta que hace gárgaras colgado en una ventana. Se desacraliza la figura del poeta como genio romántico, como sujeto visionario. El yo lírico adorna los sentimientos dolorosos de este poeta con palabras azules, es decir, con la poesía romántica. Recordemos que el color predilecto del poeta, durante el Romanticismo, es el azul (véase, al respecto, a Novalis, que cita por primera vez el símbolo romántico de la "Flor azul" (Die Blaue Blume) en su novela inconclusa Enrique de Ofterdingen (Novalis, 1951) publicada en 1802 [Shulz, 2002]). Se establece un breve diálogo entre el poeta y el yo lírico: el primero se disculpa ante el segundo por su egocentrismo. Es un poema que se burla de la melancolía del poeta romántico. Su dolor, su desesperación, su tristeza, es una pose, máscara o impostura: su voz es demasiado modosa y débil como para dejarse oír y su personalidad se diluye, desaparece en el tedio de la mañana, ante la indiferencia general.

Por su parte, en el "Poema VI" de Veinte poemas de amor y una canción desesperada (1924) de Pablo Neruda, el poeta chileno utiliza las hojas secas, aunque no como topoi independiente, sino en el marco de una imagen poética mayor:

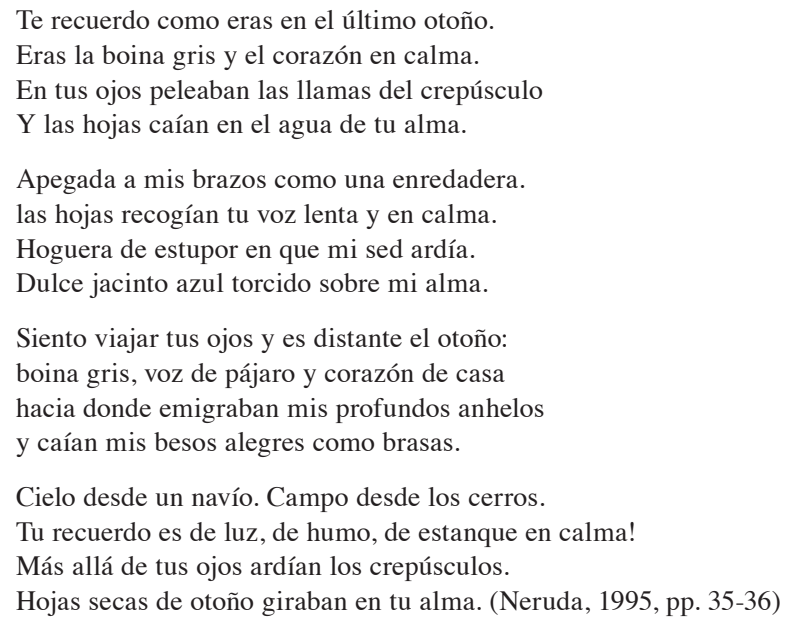

En el último otoño, ambos amantes estaban abrazados y el yo lírico recuerda cómo, en los ojos de la amada, lograba visualizar una imagen poética: la caída y el giro de las hojas en el agua de su alma. El yo lírico tiene conciencia del carácter de las hojas secas como topos fosilizado del Romanticismo. Lo asume como símbolo de toda relación amorosa: de topos se convierte en símbolo de todo vínculo sentimental. Se encuentra ausente de las hojas secas otoñales de Neruda la desesperación de una relación amorosa que se ha roto o ha terminado. Décadas y décadas de ejercicio literario del topos lo ha convertido, a nivel popular, en símbolo del amor, aunque una lectura más atenta de los poemas que lo incorporan, sobre todo los del siglo XIX, lo utilicen desde la semántica del desamor y el desengaño. Lo mismo sucede con el tópico del crepúsculo: cuando el destinario del poema lee el verso "En tus ojos peleaban las llamas del crepúsculo", mientras los amantes están abrazados, se imagina a estos últimos en un ambiente natural frente a un ocaso o atardecer donde el sol, sin obstáculos visuales que oculten su trayectoria, se pone en el horizonte, en un juego de celajes anaranjados, amarillentos y azulados. Imagina esta escenografía reflejada en el globo ocular de la amada. Asimismo, las hojas que caen en el agua del alma de la amada y que recogen su voz lenta y en calma, como 
si fueran objetos vacíos que paulatinamente se empaparan de sus atributos, nos hablan de un amor sereno que, sin estridencia, se va reforzando o construyendo día tras día. En este sentido, la metáfora orientacional de la caída no significa la muerte, sino la consolidación cotidiana de una relación afectiva. Las hojas que caen en el agua remiten a un amor fértil que se sedimenta -como un limo, como un amor nutricio-, cuya vigencia será eterna.

El peruano Jorge Eduardo Eielson (1924-2006), en el poema 10 del poemario Mutatis mutandis (1967), al igual que Maples Arce, niega los usos tópicos tradicionales del sintagma de las hojas secas $-y$, en consecuencia, las estéticas que han desarrollado estos usos- en una manifestación de la estética de la negación o del silencio:

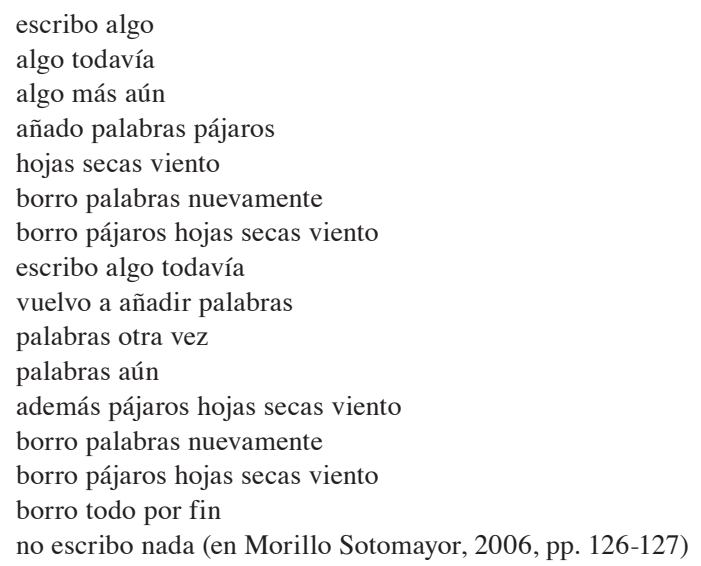

Junto con los pájaros y el viento, el yo enunciativo ha escogido las hojas secas como símbolo poético por antonomasia. De esta manera, la decisión de borrar las palabras 'pájaro', 'viento', 'hojas secas', que la voz enunciativa escribe varias veces en el mismo orden, sin permutarlas, en los diversos y vanos intentos que realiza -en el marco de su proceso creativo- para conseguir el poema perfecto, supone la renuncia a escribir poesía. El mensaje que pretende comunicar la voz enunciativa, que remite a un poeta, es el siguiente: es mejor permanecer en silencio, abandonar la escritura, antes que ofrecer clisés (monótonamente repetidos en el mismo orden); es mejor dejar en suspenso el proceso creativo antes que ofrecer una poesía carente de cualquier atisbo de innovación literaria. Por lo demás, y como ejemplo de poema gráfico, se representa espacialmente el desprendimiento y arrastre de las hojas secas por el viento al separar ligeramente estos dos últimos términos de las palabras restantes de los versos en los que se encuentran, en lo que podemos llamar como 'línea poética fragmentada en sintagmas independientes'.

\section{Conclusiones}

En términos narrativos, se pueden distinguir tres momentos del uso afectivoexistencial del tópico de las hojas secas: el del desprendimiento de la rama del árbol (inicio de la pérdida del amor o de la salud), el de la caída (empeoramiento de los nexos afectivos, empeoramiento de la salud) y el del torbellino o viento que arrastra las hojas (disolución del amor o desaparición de la salud). Cuando, en algunos casos, las hojas remontan el vuelo temporalmente gracias a un golpe de viento, se alude a una recuperación, solamente coyuntural, del amor o de la salud (y ocasionalmente de los recuerdos vivenciales). Según sus 
intereses e intenciones, los textos se sitúan en uno u otro momento de la secuencia narrativa mencionada. En este sentido, hemos podido comentar, como portada, un texto particularmente relevante por su concisión y tensión dramática, "Soldados", de Giuseppe Ungaretti, que enfoca el momento climático de las hojas en otoño, a punto de ser arrancadas por el viento, y su analogía simbólica con la situación de los soldados en el frente durante la Primera Guerra Mundial. Esa identificación entre el tópico y las situaciones de extrema fragilidad (y amenaza) la hemos percibido en los dos primeros poemas comentados en lengua española, el de Fernando Paz Castillo y Dulce María Loynaz. En ambos casos hemos de destacar una idea que late frecuentemente en los usos del tópico: la aleatoriedad, la arbitrariedad del momento exacto en que se produce la muerte o el olvido, expresado en el golpe de viento concreto que despega definitivamente el frágil cordón umbilical que une a la hoja moribunda con su tronco o tallo. Ese momento es impredecible, no se puede conocer. La focalización de esa escena contribuye a que el poema adquiera una gran tensión dramática.

Como hemos visto, la función lírica afectiva-existencial del tópico de las hojas secas en la literatura en español del siglo XIX se orienta, preferentemente, hacia la alegorización del proceso afectivo, amoroso, mientras que en el XX se vincula preferentemente hacia la semántica del proceso vital, que tiene como etapa final la muerte del sujeto humano. Por otro lado, la diferencia de tratamiento del tópico entre los siglos XIX y XX queda evidenciada en algunos poemas seleccionados como el de J. Eduardo Eielson y, especialmente, el de Maples Arce, que directamente simboliza el rechazo a la tópica de origen romántico señalando algunos tópicos, entre los que se encuentra el de las hojas secas.

Otros autores fijan su atención en otras connotaciones o momentos de la secuencia narrativa del tópico. Así, Juan José Tablada lo usa como símbolo de la dualidad vida/muerte y como imagen metafórica de la soledad, mientras que el Neruda más romántico de Veinte poemas de amor y una canción desesperada lo incorpora en la evocación otoñal nostálgica de un amor pasado.

Como todos los tópicos de larga duración, las hojas secas constituyen lo que podemos designar como un 'universal expresivo' (de la misma manera que ha sido acuñado el concepto de universal linguiístico o el de universal narrativo, este último en los estudios sobre los mitos). En consecuencia, traspasa el ámbito del discurso escrito y se manifiesta en diversos medios. Se convierte, por lo tanto, en un objeto de investigación pertinente para los estudios intermediales.

De la misma manera que han evolucionado los significados aportados por el topos de las hojas secas (del metaliterario o metalingüístico al afectivo y existencial), su plano expresivo también lo ha hecho. Se puede conservar en el tiempo el núcleo semántico (la fugacidad de las palabras, de las formas o géneros literarios, del amor, de la vida), pero el plano expresivo se puede modificar. Encontramos un precedente en el ejemplo de la novela realista La Regenta, donde las hojas han sido sustituidas por los despojos, los trapos, el polvo, los papeles y las migajas de basura. Otro mucho más reciente lo encontramos en la película Belleza americana (American Beauty), en la conocida escena de la bolsa de plástico zarandeada por el viento que los personajes Ricky Fitts y Angela Hayes ven a través de una pantalla de televisión (que sustituye a las hojas secas del discurso literario). En estos mismos términos, puede indagarse en el futuro el papel que en la literatura y en el cine han llegado a tener las colillas y las cenizas de los cigarrillos, que también aluden a la brevedad de la vida humana. Evidentemente, se sugiere la brevedad de la vida humana y la vanidad de sus sueños de grandeza. 
En suma, el tópico de las hojas secas contiene tal carga iconográfica y semántica que, acuñado en la Antigüedad, atraviesa toda la literatura europea y americana y acaba trascendiendo a otras artes. En este estudio hemos intentado mostrar algunas de las manifestaciones latinoamericanas del siglo XX más representativas del mismo, comentando sus modulaciones semánticas más importantes, la afectivo-existencial y la metaliteraria, frecuentemente unidas. Estamos, pues, ante un universal expresivo que se añade al repertorio de tópicos de base iconográfica vegetal junto al carpe diem o el collige, virgo, rosas, entre otros, todos ellos anunciando connotativamente la fugacidad irreversible de la belleza, de las corrientes literarias, del amor, de los recuerdos y, finalmente, de la vida. Futuras investigaciones podrán acercarse a sus manifestaciones en campos literarios regionales o nacionales más específicos, como el centroamericano o el argentino, entre otros.

\section{Notas}

1. En el marco de la descripción de una tormenta, el yo enunciativo declara que, cuando amenaza el viento, "con frecuencia también observarás revolotear la ligera paja y formar remolinos las hojas al caer" (Virgilio, 1963, v. 367-368).

2. Cuando Diomedes le pregunta a Glauco, antes de pelear, si procede de un linaje humano o divino, el segundo, hijo de Hipóloco, le responde: "Magnánimo Tidida! ¿Por qué me preguntas mi linaje? / Como el linaje de las hojas, tal es también el de los hombres. / De las hojas, unas tira a tierra el viento, y otras el bosque / hace brotar cuando florece, al llegar la sazón de la primavera. / Así el linaje de los hombres, uno brota y otro se desvanece" (Homero, 1991, p. 217).

3. Riesz (1984, p. 49) ha analizado e interpretado este poema y considera que admite hasta seis lecturas: (1) la biográfica, en la que el poema se comprende como expresión de la experiencia personal de Ungaretti en la I Guerra Mundial; (2) el significado que reviste el poema en el contexto del poemario al que pertenece, o en el conjunto de la obra del autor; (3) el análisis comparativo, frente a poemas de la misma época de tema análogo (la fragilidad de la vida, y en particular la de un soldado); (4) el análisis estilístico, orientado a indagar en los desvíos formales y lingüísticos del poema frente al lenguaje coloquial, donde destacan la concisión lingüística y las consideraciones gráficas; (5) el análisis diacrónico, que indaga en los posibles modelos del poema en la tradición literaria y cultural (es decir, un análisis del poema desde la tradición tópica, desde la variante o modulación de un tópico clásico, que es precisamente el tipo de investigación que realizamos en el presente artículo); y (6), un análisis antropológico y filosófico que investigue los presupuestos psicológicos e intelectuales que inciden en la elaboración de la imagen poética ofrecida por el poema (para los propósitos del presente artículo, imagen poética y tópico poético son términos intercambiables) y que se pueden resumir en la caída como fenómeno fisiológico y como metáfora orientacional.

4. Seiko Ota (2014, p. 99) considera que en el poemario Un día... Poemas sintéticos (1919) se incorporan haikus, que considera una influencia directa de la literatura japonesa en el escritor mexicano; en particular, el titulado "Hojas secas" lo considera paráfrasis de un poema de Yayu Yokoi, escritor japonés del siglo XVIII, que Tablada leería en traducción inglesa en A History of Japanese Literature, escrita por William George Aston y publicada en 1916; frente al original, Ota precisa que Tablada limita el espacio poético a un jardín, y aporta a los árboles un atributo ('verdes') y una coordenada temporal ('en primavera'). La traducción al inglés del haiku japonés es la siguiente: "o ye fallen leaves! / There are far more of you; / Than ever I saw growing on the tres" (Aston, 1916, p. 296).

\section{Bibliografía}

Álvarez Cienfuegos, N. (1987). El fin del otoño. En R. Andrés (Ed.). Antología poética del Romanticismo español. (pp. 15-17). Barcelona: Planeta. 
Aston, W. G. (1916). A History of Japanese Literature. New York: D. Appleton and Company. Bécquer, G. A. (2001). Rimas y leyendas. Madrid: Espasa-Calpe.

Böhl de Faber, J. N. (Ed.). (1827). Primera parte de la floresta de Rimas antiguas castellanas ( $2^{\mathrm{a}}$ ed). Hamburgo: Federico Perthes.

Campos, M. A. (Ed.). (2004). Poetas italianos del siglo XX. México: Universidad Autónoma de México.

Castro, R. (2016). Follas novas. Santiago de Compostela: Galaxia.

Curtius, E. R. (1955 [1948]). Literatura europea y Edad Media Latina. México: Fondo de Cultura Económica.

Cuvardic García, D. (2015). La función metapoética del tópico de 'las hojas secas' en la literatura occidental. En P. Calef y F. Estévez (Eds.). Hora fecunda. Scritti in onore Giancarlo Depretis. (pp. 409-421). Torino: Trauben.

Davis, L. G. (2002 [1997]). Resistirse a la novella. Novelas para resistir. Ideología y ficción. (R. García Pérez, Trad.). Barcelona: Debate.

Doane, M. A. (2012). La emergencia del tiempo cinemático. La modernidad, la contingencia y el archivo. Murcia: Cendeac.

González Iglesias, J. A. (2012). Introducción. En Horacio, Arte poética. (pp. 9-40). Madrid: Cátedra.

Guillén, C. (2005). Entre lo uno y lo diverso. Introducción a la literatura comparada. Barcelona: Tusquets.

Homero. (1991). Ilíada. (E. Crespo Güemes, tr.). Madrid: Gredos.

Horacio (Quinto Horacio Flaco). (2012). Arte poética. En J. A. González Iglesias (Ed.). Madrid: Cátedra.

Keats, J. (1989). Al otoño. En J. M. Valverde (tr.) Poetas románticos ingleses. Byron, Shelley, Keats, Coleridge, Wordsworth. (pp. 210-212). Barcelona: Planeta.

Lakoff, G. y Johnson, M. (1986). Metáforas de la vida cotidiana. Madrid: Cátedra.

Lamartine, A. (1841). El otoño. En J. M. de Berriozabal (tr.). Poesías. (pp. 131-133). Molins de Rey: Librería del Sr. Pablo Cases.

Loynaz, D. M. (1993). Poemas escogidos. En P. Simón (Comp.). Madrid: Visor.

Maples Arce, M. (1999). Y nada de hojas secas. En G. García Maroto (Ed.). Nueva antología de poetas mexicanos. (pp. 72-86). Madrid: Breve Fondo Editorial.

Morillo Sotomayor, A. (2006). Cuatro anudamientos de la escritura fronteriza: la poética cósmica de Jorge Eduardo Eielson. Tinta expresa, 2, 113-134.

Neruda, P. (1995). Veinte poemas de amor y una canción desesperada. Cien sonetos de amor. Barcelona: Altaya.

Novalis. (1951). Enrique de Ofterdingen. Buenos Aires: Espasa Calpe.

Ota, S. (2014). José Juan Tablada. Su haikú y su japonismo. México: Fondo de Cultura Económica. 
Paz Castillo, F. (1988). Poesía. Caracas: Biblioteca Ayacucho.

Pérez Parejo, R. (2002). Metapoesía y crítica del lenguaje (De la generación de los 50 a los novísimos). Cáceres: Servicio de Publicaciones de la Universidad de Extremadura.

Riesz, J. (1984). Falling leaves: some reflections on the nature and function of the image in lyric poetry. Yearbook of Comparative and General Literature, 33, 49-48.

Schiller, F. (1995). Sobre poesía ingenua y sentimental. Madrid: Visor.

Shulz, G. (2002). Universum und Blaue Blume: zum Gedenken an Novalis (1772-1881). Oldenburg: Bibliotheks und Informationssystem univ.

Souriau, E. (1998). Diccionario Akal de estética. Madrid: Akal.

Tablada, J. J. (1971). Hojas secas. En H. Valdés (Ed. y Comp.). Obras I. Poesía (La tarde). (p. 377). México: UNAM.

Tablada, J. J. (1971). Hotel. En H. Valdés (Ed. y Comp.). Obras I. Poesía (La tarde). (p. 377). México: UNAM.

Virgilio Marón, P. (1963). Geórgicas. México: UNAM. 